\title{
Anti-CASPR2 and Epilepsy: don't forget to think about it
}

Marco Antônio Machado Schlindwein ${ }^{1 *}$, Isabelle Pastor Bandeira ${ }^{1}$, Letícia Caroline Breis ${ }^{1}$, Guilherme Simone Mendonça ${ }^{2}$, Marcus Vinicius Magno Gonçalves ${ }^{3}$

${ }^{1}$ Medical Student - Department of Medicine, University of the Region of Joinville, Santa Catarina, Joinville, 89202-207, Brazil.

${ }^{2}$ Preceptor Epilesy department, Santa Isabel Hospital, Blumenau, Santa Catarina, Brasil.

${ }^{3}$ Professor of Neurology, Department of Medicine, University of the Region of Joinville, Santa Catarina, Joinville, 89202-207, Brazil.

*Corresponding Author: Marco Antônio Machado Schlindwein, Department of Medicine, University of the Region of Joinville, Rua Ministro Calógeras, 439, Bucarein, Joinville, Santa Catarina, Brazil,

Received date: January 11, 2021; Accepted date: April 11, 2021; Published date: April 23,2021

Citation: Machado Schlindwein MA., Isabelle P. Bandeira., Letícia C. Breis., Guilherme S. Mendonça., Marcus V. Magno Gonçalves., (2021) AntiCASPR2 and Epilepsy: don't forget to think about it. J. Neuroscience and Neurological Surgery. 8(4); DOI:10.31579/2578-8868/149

Copyright: () 2021 Marco Antônio Machado Schlindwein, This is an open-access article distributed under the terms of The Creative Commons Attribution License, which permits unrestricted use, distribution, and reproduction in any medium, provided the original author and source are credited

\begin{abstract}
Summary
Autoimmune encephalitis (AE) is an important cause of seizures. With the discovery of highly specific neuronalantibodies the recognition of the clinical syndrome associated with each marker is crucial to the right diagnosis and treatment regime. In this short review we summarize the importance of CASPR2 antibodies in unknown etiology seizures and its epileptogenesis.
\end{abstract}

Keywords: CASPR2; epilepsy; autoimmune encephalitis; autoimmune epilepsy

\section{Introduction}

Autoimmune encephalitis (AE) is a growing field in neurology. The discovery of highly specific neuronal-antibodie [1] makes a typical syndrome recognition important to reach the correct antibody diagnosis and correct treatment regimen important. Thus, it is possible to achieve the correct diagnosis of these antibodies and the eligible treatment regimen.

Seizures are a common presentation among those with AEs, with $20 \%$ of them being diagnosed with epilepsy on admission [2]. It is interesting to note that the cluster of evidence involving neuronal antibodies and epilepsy is still growing. In a study evaluating the prevalence of these antibodies in patients with new and/or established epilepsy, It was found that $11 \%$ of those had positive antibodies with antibodies against VoltageGated potassium channel (VGKC) complex, representing almost half of them [3]. A similar result occurs in a study that evaluated children with new-onset seizures, of which $9.7 \%$ had positive antineuronal antibodies with CASPR2 (the second more frequently found) [4]. In the pediatric cohort of Wright et al. (2016) the results were very similar [5].

Contactin-associated protein-like 2 (CASPR2) is a cell adhesion molecule with an important function in clustering VGKC in the juxtaparanodal region of the Node of Ranvier [6]. Together with Leucine-Rich GliomaInactivated 1 (LGI-1) protein, CASPR2 (anti-CASPR2) antibodies form among patients who have VGKC antibodies [7]. Although seizures appear more frequently in anti-LGI-1 $(80 \%)$ patients than in patients positive for anti-CASPR $2(49 \%)[8,9]$ other studies have actually shown that seizure is also a common symptom in CASPR2 antibodies disease in children [10] and in adults ${ }^{\mathbf{8}, 10,11}$ The incidence of positive antibody patients can reach up to half of the patients [8].
Curiously, the prevalence of neuronal antibodies appears to be higher in some subtypes of epileptic syndromes $[4,12,13]$. Ekizoglu and colleagues evaluated the prevalence of neuronal antibodies in patients with focalepilepsy of unknown cause and mesial temporal lobe epilepsy with hippocampal sclerosis: $16 \%$ of patients were positive for neuronal antibodies, with $4.9 \%$ of patients positive for CASPR 2 specifically [12]. In temporal lobe epilepsy, the prevalence found was $5 \%$, with antibodies. Of these, 4 patients were positive for CASPR2 [14]. Afterward, in a cohort study that included patients with late-onset epilepsy, CASPR2 was the only specific neuronal antibody found (3\%) [15].

Therefore, temporal lobe epilepsy with or without hippocampus atrophy, focal epilepsy of unknown origin, epilepsy with peri-ictal autonomic disturbance and late-onset epilepsy may place anti-CASPR2 encephalitis on the differential diagnosis table [12-15]. Epileptic activity on the initial electroencephalogram (EEG) appeared only in $30 \%$ of patients with CASPR2 [8]. Consequently, it is extremely important to pay attention to clinical details that can help clarify the diagnosis.

Among those details, we highlight: patients with advanced age, presenting with a sub-acute progressive cognitive decline, or sleep disorders, as well as psychiatric complaints of recent onset, autonomic dysfunction (especially hyperhidrosis and heart rhythm abnormalities). Other red flags may be cerebellar symptoms and impairment of the peripheral nervous system, especially neuropathic pain and neuromyotonia (Table 1) $[8,10,11,16]$. These data advise in favor of disease with positive CASPR2 antibodies. 


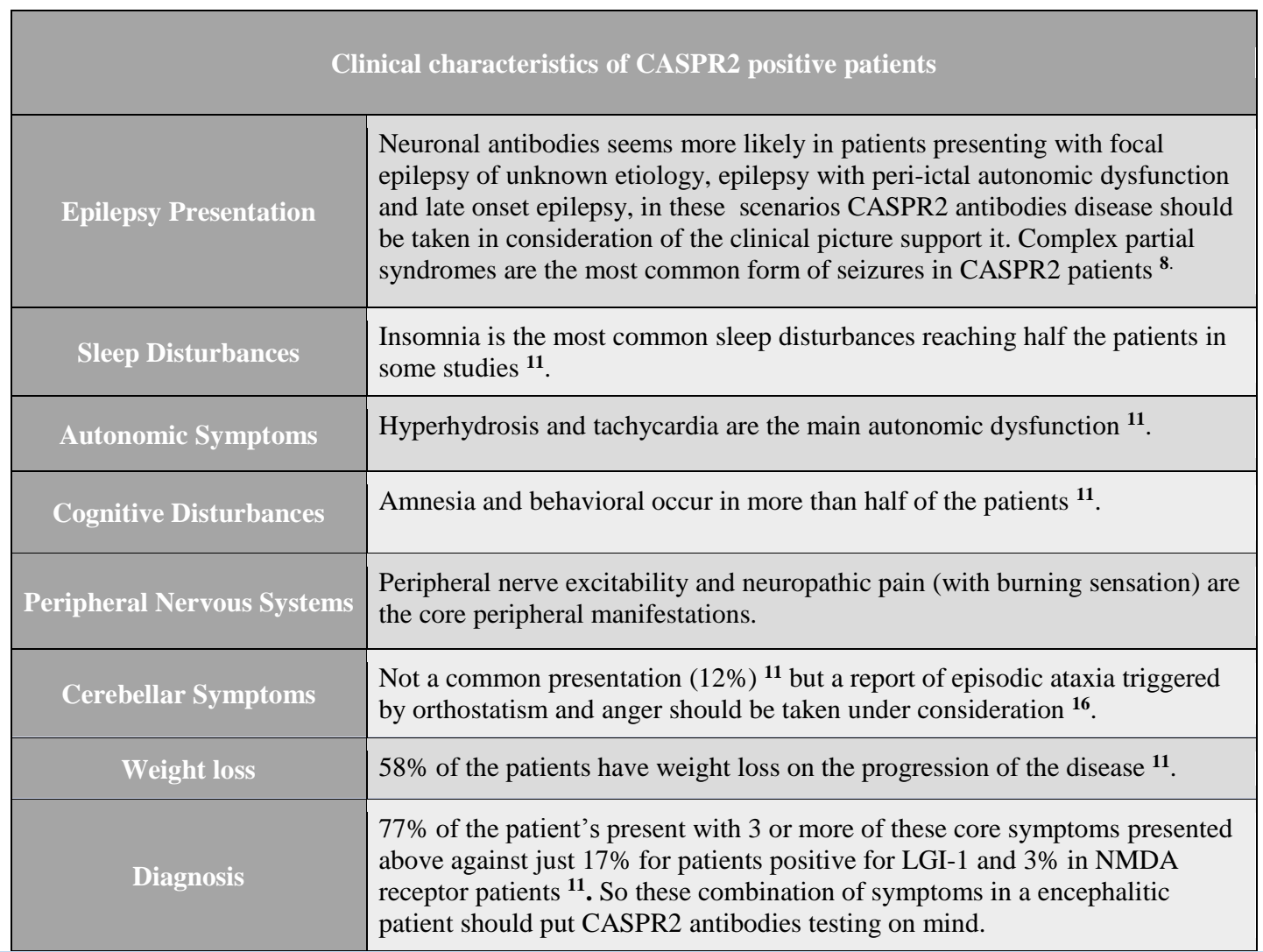

Table 1: The table discuss the epilepsy sub-types that appeared to have a more strong association with neuronal antibodies and core clinical features that should make CASPR2 antibodies diagnosis present on the differential.

In addition, a worrying fact in anti-CASPR2 encephalitis is that a great amount of the patients do not present changes in the magnetic resonance image; the image is normal, without registering $\mathrm{T} 2$ hyper-intensities $[8,10,11]$ especially in the initial presentation [8]. That is why normal imaging does not exclude AE, including anti-CASPR2 encephalitis.

These findings are probably related to the fact that CASPR2 antibodies are of the IgG4 subclass and do not activate complement, nor do they induce internalization (common features in other AE syndromes). On the other hand, disrupt the interaction between CASPR2 and transient axonal glycoprotein-1 (TAG-1) where they make the clustering of the juxtaparanode VGKC [17-19]

However, the distribution of VGKC along the axon relies on this interaction (CASPR2 and TAG-1) especially in the juxtaparanodal region, which are important for the control of neural excitability [20].

The epileptogenesis activity linked to anti-CASPR2 antibodies is not completely defined, although there is evidence that these antibodies target the inhibitory neurons in the hippocampus [21] causing an increase in the VGKC and reducing the activity of these neuronal cells [19]. It is believed that this cascade of phenomena results in an increase in the triggering activity of the CA3 neurons in the hippocampus, giving rise to the seizure crisis [22]. Also, functional neuroimagem studies have already reported abnormalities in the hippocampus associated with anti-CASPR2 patients [23], whilst this has been correlated with amnesia and not with epileptic activity itself.

In conclusion, CASPR2 antibodies often present with seizures, and the primary diagnosis for these patients may be epilepsy. Therefore, a carefully clinical evaluation can help guide the screening of antibodies and the establishment of the correct treatment. Finally, further studies are needed to elucidate the pathogenesis of epilepsy associated with antiCASPR2, and thus complement the puzzle of Unknown Etiology Seizures

\section{Acknowledgements}

None

\section{Disclosure of conflict of interest}

None of the authors has any conflict of interest to disclose.

\section{Ethical Publication Statement}

We confirm that we have read the Journal's position on issues involved in ethical publication and affirm that this report is consistent with those guidelines.

\section{References}

1. Lang K, Prüss H. Frequencies of neuronal autoantibodies in healthy controls: Estimation of disease specificity. Neurol Neuroimmunol Neuroinflamm. 2017;4(5):e386. Published 2017 Jul 18. doi:10.1212/NXI.0000000000000386

2. Baumgartner A, Rauer S, Hottenrott $\mathrm{T}$, et al. Admission diagnoses of patients later diagnosed with autoimmune encephalitis. J Neurol. 2019;266(1):124-132. doi:10.1007/s00415-018-9105-3

3. Brenner T, Sills GJ, Hart Y, et al. Prevalence of neurologic autoantibodies in cohorts of patients with new and established epilepsy. $\quad$ Epilepsia. 2013;54(6):1028-1035. doi:10.1111/epi.12127

4. Suleiman J, Wright S, Gill D, et al. Autoantibodies to neuronal antigens in children with new-onset seizures classified according to the revised ILAE organization of seizures and epilepsies. Epilepsia. 2013;54(12):2091-2100. doi:10.1111/epi.12405 
5. Wright S, Geerts AT, Jol-van der Zijde CM, et al. Neuronal antibodies in pediatric epilepsy: Clinical features and longterm outcomes of a historical cohort not treated with immunotherapy. Epilepsia. 2016;57(5):823-831. doi:10.1111/epi.13356

6. Saint-Martin M, Joubert B, Pellier-Monnin V, Pascual O, Noraz N, Honnorat J. Contactin-associated protein-like 2, a protein of the neurexin family involved in several human diseases. Eur J Neurosci. 2018;48(3):1906-1923. doi:10.1111/ejn.14081

7. Irani SR, Alexander S, Waters $\mathrm{P}$, et al. Antibodies to Kv1 potassium channel-complex proteins leucine-rich, glioma inactivated 1 protein and contactin-associated protein- 2 in limbic encephalitis, Morvan's syndrome and acquired neuromyotonia. Brain. 2010;133(9):2734-2748.

8. Gadoth A, Pittock SJ, Dubey D, et al. Expanded phenotypes and outcomes among 256 LGI1/CASPR2-IgG-positive patients. Ann Neurol. 2017;82(1):79-92. doi:10.1002/ana.24979

9. Nosadini M, Toldo I, Tascini B, et al. LGI1 and CASPR2 autoimmunity in children: Systematic literature review and report of a young girl with Morvan syndrome. J Neuroimmunol. 2019;335:577008. doi:10.1016/j.jneuroim.2019.577008

10. Boyko M, Au KLK, Casault C, de Robles P, Pfeffer G. Systematic review of the clinical spectrum of CASPR2 antibody syndrome. J Neurol. 2020;267(4):1137-1146. doi:10.1007/s00415-019-09686-2

11. van Sonderen A, Ariño H, Petit-Pedrol M, et al. The clinical spectrum of Caspr2 antibody-associated disease. Neurology. 2016;87(5):521-528. doi:10.1212/WNL.0000000000002917

12. Ekizoglu E, Tuzun E, Woodhall $\mathrm{M}$, et al. Investigation of neuronal autoantibodies in two different focal epilepsy syndromes. $\quad$ Epilepsia. 2014;55(3):414-422. doi:10.1111/epi.12528

13. Baysal-Kirac L, Tuzun E, Erdag E, et al. Neuronal autoantibodies in epilepsy patients with peri-ictal autonomic findings. J Neurol. 2016;263(3):455-466. doi:10.1007/s00415-015-8002-2

14. Elisak M, Krysl D, Hanzalova J, et al. The prevalence of neural antibodies in temporal lobe epilepsy and the clinical characteristics of seropositive patients. Seizure. 2018;63:1-6. doi:10.1016/j.seizure.2018.09.00

15. von Podewils F, Suesse M, Geithner J, et al. Prevalence and outcome of late-onset seizures due to autoimmune etiology: A prospective observational population-based cohort study. $\quad$ Epilepsia. 2017;58(9):1542-1550. doi:10.1111/epi.13834

16. Joubert B, Gobert F, Thomas L, et al. Autoimmune episodic ataxia in patients with anti-CASPR2 antibody-associated encephalitis. Neurol Neuroimmunol Neuroinflamm. 2017;4(4):e371. Published 2017 Jun 14. doi:10.1212/NXI.0000000000000371

17. Patterson KR, Dalmau J, Lancaster E. Mechanisms of Caspr2 antibodies in autoimmune encephalitis and neuromyotonia. Ann Neurol. 2018;83(1):40-51. doi:10.1002/ana.25120

18. Davies AM, Sutton BJ. Human IgG4: a structural perspective. Immunol Rev. 2015;268(1):139-159. doi:10.1111/imr.12349

19. Saint-Martin M, Pieters A, Déchelotte B, et al. Impact of antiCASPR2 autoantibodies from patients with autoimmune encephalitis on CASPR2/TAG-1 interaction and Kv1 expression. J Autoimmun. 2019;103:102284. doi:10.1016/j.jaut.2019.05.012

20. Pinatel D, Hivert B, Saint-Martin M, et al. The Kv1associated molecules TAG-1 and Caspr2 are selectively targeted to the axon initial segment in hippocampal neurons. J Cell Sci. 2017;130(13):2209-2220. doi:10.1242/jcs.202267

21. Pinatel D, Hivert B, Boucraut $\mathrm{J}$, et al. Inhibitory axons are targeted in hippocampal cell culture by anti-Caspr2 autoantibodies associated with limbic encephalitis. Front Cell Neurosci. 2015;9:265. Published 2015 Jul 9. doi:10.3389/fncel.2015.00265

22. Romoli M, Krashia P, Sen A, et al. Hippocampal epileptogenesis in autoimmune encephalitis. Ann Clin Transl Neurol. 2019;6(11):2261-2269. doi:10.1002/acn3.50919

23. Loane C, Argyropoulos GPD, Roca-Fernández A, et al. Hippocampal network abnormalities explain amnesia after VGKCC-Ab related autoimmune limbic encephalitis. J Neurol Neurosurg Psychiatry. 2019;90(9):965-974. doi:10.1136/jnnp-2018-320168

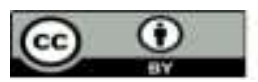

This work is licensed under Creative Commons Attribution 4.0 License

To Submit Your Article Click Here: Submit Manuscript

DOI:10.31579/2578-8868/149
Ready to submit your research? Choose Auctores and benefit from:
fast, convenient online submission
rigorous peer review by experienced research in your field
rauth publication on acceptance
imique DOI for all articles
At Auctores, research is always in progress.
Learn more www.auctoresonline.org/journals/neuroscience-and-
neurological-surgery 